\title{
A Study on the Aesthetic Style of Hong Kong Film in the New Wave Movement
}

\author{
Weiqing Sun, Bo Zhang \\ Department of Film and Television Arts, Shanghai Publishing and Printing College, Shanghai, China \\ Email: 309752339@qq.com
}

How to cite this paper: Sun, W. Q., \& Zhang, B. (2020). A Study on the Aesthetic Style of Hong Kong Film in the New Wave Movement. Open Journal of Social Sciences, 8 , 53-60.

https://doi.org/10.4236/jss.2020.88005

Received: July 18, 2020

Accepted: August 11, 2020

Published: August 14, 2020

Copyright $\odot 2020$ by author(s) and Scientific Research Publishing Inc. This work is licensed under the Creative Commons Attribution International License (CC BY 4.0).

http://creativecommons.org/licenses/by/4.0/

\begin{abstract}
This paper mainly studies the new wave movement of film in Hong Kong from the late 1970s to the early 1980s. Through the analysis of its background, the transformation of aesthetic style and the inspiration and significance of the new wave film to the later Hong Kong film, we can feel the unique charm and style of the new wave film.
\end{abstract}

\section{Keywords}

New Wave of Hong Kong, Aesthetic Style, Implication

\section{The Background and Naming of the New Wave Film Trend in Hong Kong}

Emerged in the late 1970s to the beginning of 1980s, the new wave film is a vital part of Hong Kong film industry. Although it was born in time when Hong Kong enjoyed a booming economic growth, the new wave film's achievement in art is prominent, exerting profound impact on the film then and even the film in this new century, and rising as the cornerstone of the "New movement of Asia in the film industry" (Fu, 2017). The young directors who are emerged in this time have conducted a series of transformations from the theme of the film to the film camera language from their unique understandings and perspective, empowering the Hong Kong film movement to be one of the most significant and far-reaching.

At the end of 1970s, Hong Kong has to some extent made a great breakthrough, transforming from a developing one to a modernized one. By the virtue of the fast economic growth during the 1960s and 1970, Hong Kong surprisingly shifted from the resource-deprived area to the hub of international finance with prosperous manufacturing industry and booming import and export trade, and 
advanced service sector. It is a fairly modernized city. Hong Kong in China together with Korea, Singapore, and Taiwan in China are named as the "Four Asian Loong", a miracle of the world economy. Advanced economy usually is accompanied with a booming culture. And it was in this period that Hong Kong's free entertaining activity for the mass has enjoyed an unprecedented development. TV almost provided the public everything from soap opera, and variety show to the live-streaming for the Charity fund-raising activity with full participation. As the society there becomes more complicated and diverse, people have different demand, information, recreations and culture. The existing movie industries can no longer meet the demand of their audience. Therefore, those young directors once working in some radio stations noticed the flourishing society and the audience's new demands, promoting the birth of the new film movement in Hong Kong.

Hong Kong new film movement owed its formation to a batch of excellent young directors who were born before and after the 1950 with the majority of them studying in Europe and America for film course. After finishing their studies and years of work at some TV station, they have accumulated rich experience in shooting feature films and had a good command of film language (Lin, 2018). Later, many of them have changed their focus from the TV industry to the movie industry, and striven for making movies with profound connotation, sincere feeling and unique style, thus injecting new vitality to the gloomy local movie industry, and opened a new chapter for the movie industry never seen before. The then critic scene viewed them as the "new wave", represented by $\mathrm{Xu}$ $\mathrm{Ke}$, Xu Anhua, Fang Yuping, Yan Hao, Zhang Guoming, Tan Jiaming and Zhang Jianting. At the end of 1978, Eggplant Curry, directed by Yan Hao, became the pioneer of the new wave of film because of its unique style. After that, $\mathrm{Xu}$ Anhua, Xu Ke, Tan Jiaming and other directors also started their film creation, which had a profound impact on the later Hong Kong film circle.

This paper mainly studies the new wave movement of film in Hong Kong from the late 1970s to the early 1980s. Through the analysis of its background, the transformation of aesthetic style and the inspiration and significance of the new wave film to the later Hong Kong film, we can feel the unique charm and style of the new wave film.

\section{Aesthetic Characteristics of Hong Kong's New Wave Films}

To a certain extent, the so-called "new" in the new wave of Hong Kong means that it is separated from the tradition, and it is also a double innovation and experiment from the content to the form. They get rid of the heavy national aspirations of Hong Kong Cantonese films in the 1950s and 1960s. They express a strong urban color and local sensibility in the content, and pursue the innovation of film language in form. Many of them have accumulated experience in the field of Hong Kong television and found inspiration from the French "new wave" film movement. With relatively sophisticated technology, they have sub- 
verted the traditional film language by using close-up shots, split pictures and fast-paced editing.

1) Local consciousness and humanistic spirit in ideological theme

Some people said that Hong Kong was neither a city with complete absorption of western culture nor a traditional Chinese city. It is a city with the mixture of western culture and Chinese culture. Meanwhile, it is a commercial city suffering from the colonial rule. Hong Kong culture was based on the Chinese culture with Lingnan culture as its main form. It is a kind of unorthodox, non-standard, rebellious and pluralistic cultural form. At the same time, containing the citizens and secular culture whose main cultural image is the urban civilians in the market society.

After experiencing economic transformation, Hong Kong has witnessed a rapid increase in population, thus changing the society's demographic structure. A brand-new generation grew up in a relatively rich society and nurtured by the western culture, having less feeling about their parents' memory of Chinese mainland with the Hong Kong people's innate strong departmentalism (Wang, 2017). Under the direct impact of foreign culture, people in this time have totally different mindset, values, behaviors and tastes. As the leading force, they are bound to have the demand to make movies emphasizing entertainment instead of the nationality and history. Therefore, the transformation of Hong Kong's films is inevitable. It is featured by the connotation of the film's theme more localized, an inevitable result of the transformation of Hong Kong society and culture in artistic creation.

The new wave generation is basically a generation who born or grew up in Hong Kong (Wang, 2019). When they grew older, what they care about is the local and urban tradition. Unlike those from mainland like Zhu Shilin, Li Hanxiang, $\mathrm{Hu}$ Jinquan and Zhang Che, they lack a strong, natural feeling for Hong Kong. Based on the social background at that time and the local characteristics the majority of films and TV works in the new wave period of Hong Kong represent a strong humanistic spirit when displaying the diverse life and mentality of today's Hong Kong people and Hong Kong's localization mission. Their keen sense of reality and the ability to display the local style and features are unmatched. For example, in Tsui Hark's film Type I Ddanger, the theme of the film directly points to the reality of contemporary Hong Kong, and describes the social class contradictions and ordinary people's sense of being forced with a kind of extreme point of view and technique. In this films, Hong Kong, a modernized international metropolis, becomes a solid prison, repressing personality and no freedom, where everyone are trapped but cannot find a way out, crushing and dying (Zhang \& Jia, 2019). On top of that, the biggest feature of films in this new wave is its capability to force people to notice and identify the local culture through the sway of Hong Kong's iconic things. Therefore, understanding the way the directors express their own ideas and the way to reflect the collective consciousness in the movies is one part, while analyzing how they display local culture and seek identity is another part. In the movie The Mad Rubbery 
directed by $\mathrm{Xu}$ Anhua, the story was set in a complicated murder case in the western district of Hong Kong and vividly constituted a painting with strong local characteristics by purposefully shaping the Hong Kong's folk customs like old alleys, burning ghost money, chopping chicken's head. As a director with great characteristics in Hong Kong's new wave films, Fang Yuping also focuses on his personal experience and collective memories (Qin \& Chen, 2020). In the film Father and Son, its story is based on real people and real events, and even made real people act. At the same time, the film is also the collective memory of Hong Kong people in the 1950s and 1960s, which vividly shows the semi ideal and semi realistic situation of the Hong Kong people in the real society. Most of Hong Kong's new wave films follow the road of realism, focusing on the state of local individuality. Most of their films start from the individual and then expand to the whole society, including rich personal experience and life training, and project the director's own ideas.

2) The use of subversive new film lens language

Different from the "anti Hollywood" mindset in Taiwan's new film movement, no matter in terms of production methods, packaging techniques or film technology, Hong Kong's new wave film are actually "pro-Hollywood" in film lens language. They are eager to create the external real appearance through superb artistic skills, with a strong desire to change the status quo of Hong Kong films. To a certain extent, the revolution of form is due to the change of its content. The awakening of local consciousness also arouses the film's ontological consciousness, thus reconstructing its narrative pattern and film language system (Cheung, 2017). Therefore, Hong Kong's new wave film breaks through the traditional film language paradigm of "film drama" in terms of film narrative and film language, relying on the unique audio-visual elements of film art to directly convey the film connotation and expressing the unique artistic feeling and life experience of young film makers.

First of all, the new wave films in Hong Kong adopt the montage and multi angle narration approach. This kind of structure is completely subject to the overall linear structure and causal logic, which makes the film narrative more vivid and clear. To set a plot of "killing a woman case" in "CID" shot by an Hua as an example, this goes like that the girl's father is sitting in the living room, while the girl lying in bed sleeping, at the same time, the girl's mother is chopping meat (Wei \& Li, 2018). As she cuts meat more frequently, scenes of meat cutting are reflected in his father's spectacles. Later, the picture shows a close-up of the girl walking upstairs with a bowl of noodles in her hand, followed by her mother's quickly-moving hands as she cuts meat. Then the bowl full of noodles fell from the girl's hand. At this time, the girl woke up from her dream and ran to her father in the living room and said, "Dad, I see a lot of blood". Although his father was afraid, he still comforted the girl that it was just a dream. Then, the camera shows the girl hugging her father tightly to keep him from leaving. This parallel montage, which narrates three lines at the same time, connects the girl's dream and reality. At the same time, it also exaggerates her father's tense state 
and indicates his behavior of killing his daughter the next day. At the same time, the narrative rhythm of the new wave movies is bright and concise, by the frequent application of the short lens to create a strong sense of rhythm. Tsui Ke, the director with the most outstanding personality and the most bizarre style, uses close-up and quick splicing to create a thrilling effect, which has become a classic "Tsui Ke characteristics" film narrative method, like the killing butterfly in the film "butterfly transformation" kills the Lord Shen and the scene in the film "Type I Danger" that Lin Qizhen throws a cat from the window and dies miserably on the big nails. In terms of camera movement, screen modeling and composition, new wave films pay attention to creating audio-visual impact and strive to attract the audience to the greatest extent. For example, the high-speed photography, exaggerated composition and weird character modeling in the movie "Hell without Door" are used to reflect and reveal the modern viewpoint that human nature is evil and bloodthirsty under the turbulent and oppressive real society. And in the film "Point to Soldiers", Zhang Guoming pays great attention to the application of light source when shooting and depicting the friction between the police and the murderer. He deliberately uses a natural light source to create a more realistic scene, in which the police's anxious psychological state can be more vividly reflected. These films of the new wave emphasize and highlight the individuality, try to strike a balance between satisfying the individual and the audience, while attaching a particular attention to satisfying the audience, so as to pursue the greatest commercial success. These films attach great importance to the innovation of film language, and are good at creating the real and external appearance with relatively new techniques, forming the real, vivid, bold, full and impressive visual effects.

\section{The Pursuit and Significance of Film Aesthetics under the Background of New Wave}

On the whole, the aesthetic characteristics of Hong Kong films in the context of the New Wave are inseparable from their aesthetic pursuits. Therefore, the innovation of the aesthetic characteristics is to better interpret its aesthetic pursuit and meaning in movies.

In Hong Kong, any breakthrough in film aesthetics and innovation in form are promoted by trade. In other words, in the process of film-making, every directors have never forgotten the audience and market and push forward the old tradition that emphasizes the taste of viewers and the demand of market value rules, Therefore, the ultimate goal of any innovations in film language, to some extent, is to further increase the commercial value of Hong Kong movies instead for the sake of aesthetics. Attaching great attention to the film's viewing effects is just to cater to the audience, thus winning high box office.

This feature of the new wave film movement shows the basic rule of survival for film workers in the context of commercialization and fierce competition in the film market. Therefore, most of their films are in the exploration of commercial types, and integrating into the mainstream of commercial films will be 
their ultimate trend. Therefore, in Hong Kong, which is determined by the box office, films with the public as the main viewing object, whether as an art form or as a media, always rely on the box office revenue to maintain their survival and expand reproduction. Directors of the new wave have consciously obeyed by this law since the beginning of film creation. Therefore, the new wave film movement in Hong Kong has an important impact on the prosperity of Hong Kong film. Their film creation not only improved the ideological and artistic quality of Hong Kong films as a whole, but also quickly integrated into the mainstream film creation with new ideas and new skills, and established a film narrative strategy aimed at the audience, laying a multi aesthetic foundation in the "new wave" period. Until then, Hong Kong film has completed its localization and provided quite a number of film practitioners to the Hong Kong film industry. At the same time, it has improved the new wave movement in Hong Kong lasted only two or three years. Among them are the directors like Yan Hao, Xu Anhua and Xu Ke. More mature films appeared in the middle and late 1980s. Therefore, the greatest contribution of the new wave to Hong Kong film is not in the artistic value of the film itself, but in the fact that it has trained a large number of talents for Hong Kong film, and given some young people with new ideas the opportunity to enter the film industry. At the same time, it has brought new ideas and new vision to the Hong Kong film. The avant-garde concept and method of film language in Hong Kong's new wave has greatly broadened people's horizons, thus transforming the situation of mainstream films, updating their production methods and packaging techniques; in addition, the neutralization of its operation makes it easy for ordinary filmmakers and movie audiences to accept, so as to transform films with different categories and styles, thus forming a new diversified film creation scenario. These directors emerged in the new wave later dominated the Hong Kong film industry for 20 years. Although they have developed in different ways, the late 1970s were indeed the time when they were in the leading position. They also spiritually inspired a new wave in Taiwan in China and the mainland.

The new wave movement in Hong Kong lasted only two or three years. Among them are the directors like Yan Hao, Xu Anhua and Xu Ke. More mature films appeared in the middle and late 1980s. Therefore, the greatest contribution of the new wave to Hong Kong film is not in the artistic value of the film itself, but in the fact that it has trained a large number of talents for Hong Kong film, and given some young people with new ideas the opportunity to enter the film industry. At the same time, it has brought new ideas and new vision to the Hong Kong film. The avant-garde concept and method of film language in Hong Kong's new wave has greatly broadened people's horizons, thus transforming the situation of mainstream films, updating their production methods and packaging techniques; in addition, the neutralization of its operation makes it easy for ordinary filmmakers and movie audiences to accept, so as to transform films with different categories and styles, thus forming a new diversified film creation scenario. These directors emerged in the new wave later dominated the Hong 
Kong film industry for 20 years. Although they have developed in different ways, the late 1970s were indeed the time when they were in the leading position. They also spiritually inspired a new wave in Taiwan in China and the mainland.

\section{Conclusion}

Generally speaking, by studying the aesthetic characteristics and aesthetic pursuits of the Hong Kong New Wave films, it is not difficult for us to find that Hong Kong New Wave has made bold explorations and innovations in film technology, production level, and packaging techniques from the very beginning, and kept close pace with the technology and production development of Hollywood, many films have reached the international advanced level in terms of photographic composition, color control, use of natural light, and clean and neat editing. They have not paid too much attention to the authenticity of the subject matter of the story, but rather, strove to create the external real appearance with superb artistic skills, resulting in a bold, full, and impactful visual effect. Of course, in the current era, classic movies are also able to be re-presented through new technical means, such as the virtual reality technology.

After this aesthetic transformation, Hong Kong films have absorbed the successful exploration in forms at this "new wave" period and also attracted a large number of brilliant talents, forming a more mature movie forms, and becoming a film full of post-modernism that can deconstruct all authorities and oriental moral restriction. All of those have laid a solid foundation for the coming of the period of stylization of Hong Kong films and paved the path for the future generation to enter the international film industry. After the completion of the localization framework, Hong Kong film has become more mature, and stands proud in the world film industry with its distinctive local characteristics, which constantly inspires subsequent directors to strive for the revitalization of Hong Kong film.

\section{Acknowledgements}

This work was funded by the 2019 Shanghai Art Science Planning Project, "Research on the Application of Narrative Virtual Reality (VR) Art in Shanghai Museum", project number: YB2019C02.

\section{Conflicts of Interest}

The authors declare no conflicts of interest regarding the publication of this paper.

\section{References}

Cheung, W. (2017). An Evaluation of the New Wave Cinema in Hong Kong through the Study of Four Director: Patrick Tam, Allen Fong, Ann Hui and Tsui Hark (pp. 10-12). Ph.D. Dissertation, Hong Kong: University of Hong Kong.

Fu, L. (2017). Hong Kong's Film Aesthetics-From the Perspective of Aestheticization of Everyday Life. Science \& Technology for China's Mass Media, No. 6, 232-234. 
Lin, C. C. (2018). On Hong Kong New Wave Cinema. Chinese Literature, No. 3, 84-92.

Qin, Y., \& Chen, H Z. (2020). Pseudo Art and Real Business: the Performance Strategy of Karwai Wong Film in the Commercial Context. Film Review, No. 20, 1-3.

Wang, D. L. (2019). Artistic Color and Personality Characteristics of Karwai Wong Film Music. Film Literature, No. 4, 36-39

Wang, L. (2017). Karwai Wong Film from the Perspective of "Author Movie" Theory (pp. 32-34). Taiyuan: Shanxi University.

Wei, C. J., \& Li, J. W. (2018). The Grandmaster: New Thinking of Kung Fu and Postmodern Examination. Film Review, No. 17.

Zhang, B. Q., \& Jia, L. L. (2019). History of Contemporary Chinese Film Development (pp. 114-115). Beijing: Culture and Art Press. 